\title{
A standard for rotatory power measurement
}

\author{
Andreas Brüge ${ }^{1}$, Harald Pfeiffer ${ }^{2}$ \\ ${ }_{1}^{1}$ Physikalisch-Technische Bundesanstalt (PTB), Bundesallee 100, 38116 Braunschweig, Germany \\ 2 Physikalisch-Technische Bundesanstalt (PTB), Abbestraße 2-12, 10587 Berlin, Germany
}

\section{ABSTRACT}

In Germany, the realisation and dissemination of the unit of rotatory power is a legal task of the national metrology institute aimed at ensuring the safe operation of ergometers for patients. At the Physikalisch-Technische Bundesanstalt, this task is carried out by means of a standard that can be operated both as a regulated brake and as a regulated drive, so that the effective torque and the revolution speed can be measured traceably. In this article, technical details and uncertainty calculations about this standard are given.

\section{Section: RESEARCH PAPER}

Keywords: power measurement, ergometer, standard, medical devices, uncertainty

Citation: Andreas Brüge, Harald Pfeiffer, A standard for rotatory power measurement, Acta IMEKO, vol. 8, no. 3, article 9, September 2019, identifier: IMEKO-ACTA-08 (2019)-03-09

Editor: Min-Seok Kim, KRISS, Republic of Korea

Received March 1, 2018; In final form July 1, 2019; Published September 2019

Copyright: This is an open-access article distributed under the terms of the Creative Commons Attribution 3.0 License, which permits unrestricted use, distribution, and reproduction in any medium, provided the original author and source are credited

Corresponding author: Andreas Brüge, e-mail: andreas.bruege@ptb.de

\section{INTRODUCTION}

\subsection{Retrospection}

In the 1960s, the first ergometer test benches were based on lever-mass systems, whose measurement uncertainty of about 2 $\%$ was suitable for the performance of the then friction-braked ergometers [1]. With the advent of non-contact braking methods, it became possible to raise ergometer monitoring to a new level. For this purpose, manufacturers submitted a proposal for a rotational calibration device together with a demand for traceability [2]. In addition, the Physikalisch-Technische Bundesanstalt (PTB) set the minimum requirements for ergometers [3] to ensure this traceability. The increased requirements can be fulfilled on the test equipment side using torque transducers, which, in a simple case, work as reaction transducers without rotation. For the highest requirements, they are located in the drive train as rotation transducers. The qualitative analysis of the measurement uncertainty influences on such rotating transducers undertaken by Wegener and Andrea [4] as well as experimental approaches [5] show that the transfer of the findings on non-rotating torque transducers to rotating transducers is a key element in the traceability of systems for the measurement of rotatory power.

Although ergometer calibrations are always performed in stationary states of constant revolutions, older literature occasionally speaks of 'dynamic power measurement' [6]. To avoid confusion with the measurements that are actually carried out dynamically, like in test benches of the automotive industry, recent work refers exclusively to 'rotatory power measurement'.

\subsection{Ergometry today}

In Germany, the medical assessment of the physical capabilities of patients is mainly based on measurements carried out with so-called 'foot crank ergometers'. These ergometers are considered as medical devices with a measuring function and must, in accordance with the Medical Devices Act (in German: Medizinproduktegesetz - MPG) [7] and the subordinate documents Medical Products Operating Ordinance (in German: MedizinprodukteBetreiberverordnung - MPBetreibV) [8] and the Guideline on Metrological Checks of Medical Devices with a Measuring Function (in German: Leitfaden zu messtechnischen Kontrollen von Medizinprodukten mit Messfunktion - LMKM) [9], be traceably linked to national standards at regular intervals. The task of the PTB is thus to make a national standard available which is suited to ensure the traceability of rotatory power measurements and complies with the requirements of the traceability chain from the national standard down to the ergometers. As a further development of a testing facility developed at PTB [10], 'dyncal 100' has been operated as such a standard at PTB since 2004. Its metrological properties are described in this article. In the following sections, 'standard' is used to refer to this specific national standard for rotatory power. When other standards are mentioned, their full designation is always used. 


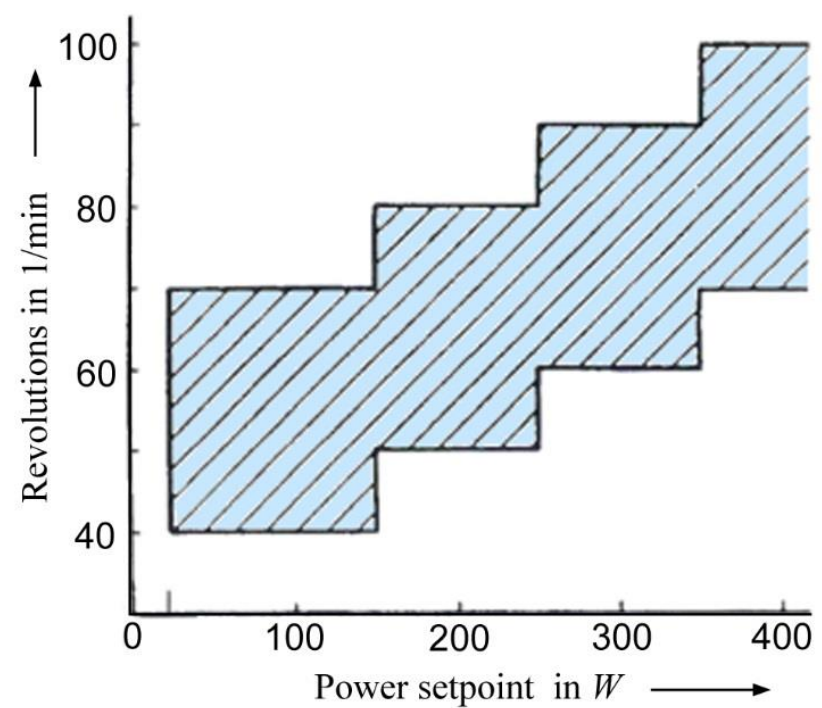

Figure 1. Working range of a foot crank ergometer in accordance with DIN VDE 0750-238. In this range, the ergometer must be able to keep the input power constant, corresponding to the power value set, within the measurement uncertainty and regardless of the revolution speed.

All symbols, abbreviations, and designations used in this paper are collected in alphabetical order in the Glossary at the end of this article.

\section{REQUIREMENTS PLACED ON A NATIONAL STANDARD}

\subsection{The traceability chain}

In accordance with 'MPBetreibV', medical ergometers must, at regular intervals, undergo a so-called 'metrological check'. Thereby, comparisons with a working standard (testing device) must be performed within the working range of the ergometer (Figure 1), which spans the range of the permitted values for revolution speed and power. The testing device thereby drives the crankshaft of the ergometer with a defined revolution speed, whereas the ergometer keeps a specified power constant by means of a regulated braking facility. From the values of the revolution speed and the torque measured by the testing device at the crankshaft, the power input of the ergometer is determined and compared with the specified power set at the ergometer.

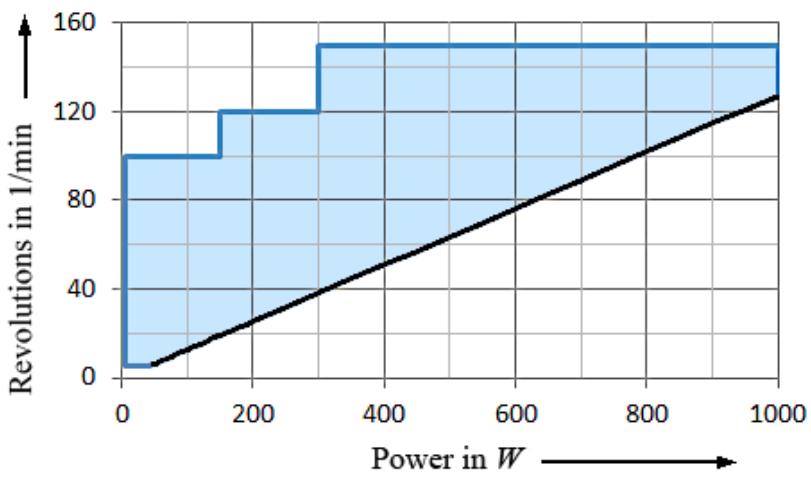

Figure 2. Working range for the revolution speed of the national standard for rotatory power in the braking mode. In this range, the standard must be able to keep the input power constant, corresponding to the power value set, within the measurement uncertainty and regardless of the revolution speed that has been fed in.

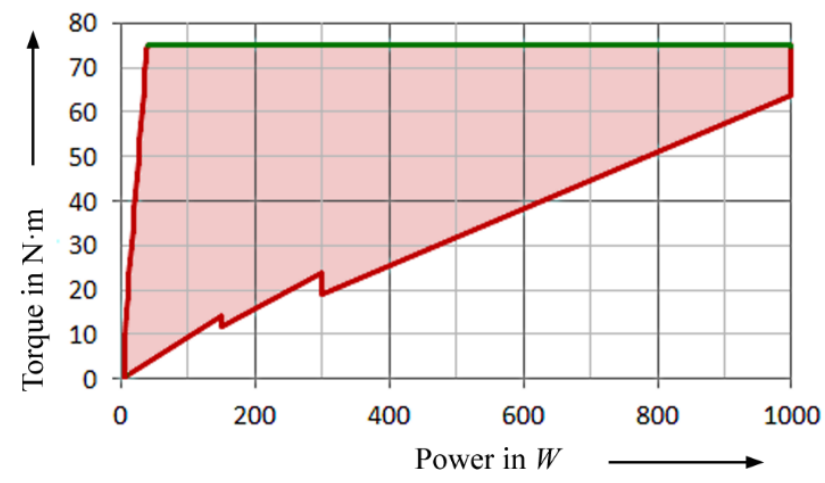

Figure 3. Working range for the torque of the national standard for rotatory power in the braking mode.

Thereby, the deviation of the indication of the power measurement of the testing device may not exceed a third of the deviation of the indication of the ergometer under test ('onethird requirement').

The testing devices, in turn, are traced back by means of reference standards that are operated in calibration laboratories and are directly linked to the national standard at PTB.

The national standard must thus exhibit measurement uncertainties, which, in the course of the dissemination via the three subordinated levels described above, maintain a sufficient margin to the measurement uncertainties of the ergometer.

\subsection{Measurement uncertainty limits}

Because ergometers in Germany are mostly conceived in accordance with the standard DIN VDE 0750-238 [11], the requirement that this standard places on ergometers can be considered as the minimum requirement. According to the DIN VDE standard, the deviation of the power indication may not exceed $5 \%$ or $3 \mathrm{~W}$, depending on which of the values is greater. The deviation of the revolution speed indication may not exceed $2 \mathrm{~min}^{-1}$.

Numerous manufacturers, however, specify a maximum deviation of the indication of $3 \%$ for their ergometers, such that this value is used as a guideline for testing devices.

In accordance with the abovementioned 'one-third requirement' laid down in MPBetreibV, the testing device must, in this case, exhibit deviations of the indication smaller than $1 \%$ or $1 \mathrm{~W}$ for the power, and smaller than $0.7 \mathrm{~min}^{-1}$ for the revolution speed. If the factor 3 is also applied to the other levels of traceability, the national standard should be able to comply with deviations of the indication of approximately $0.1 \%$ or $0.1 \mathrm{~W}$ for the power, and $0.05 \%$ for the revolution speed in the working range.

With the coverage being $k=2$, there is a requirement for relative, expanded measurement uncertainties of $0.2 \%$ - or $0.2 \mathrm{~W}$ for the power - and $0.1 \%$ for the revolution speed, respectively.

\subsection{Further requirements}

In the traceability chain described above, ergometers act - as a matter of principle - as brakes, since this is their actual mode of operation when a patient feeds in power via the foot crank. As a consequence, the testing devices must be designed as drives, and the reference standards of the next highest level must, in turn, operate as brakes. To be able to directly link both the 


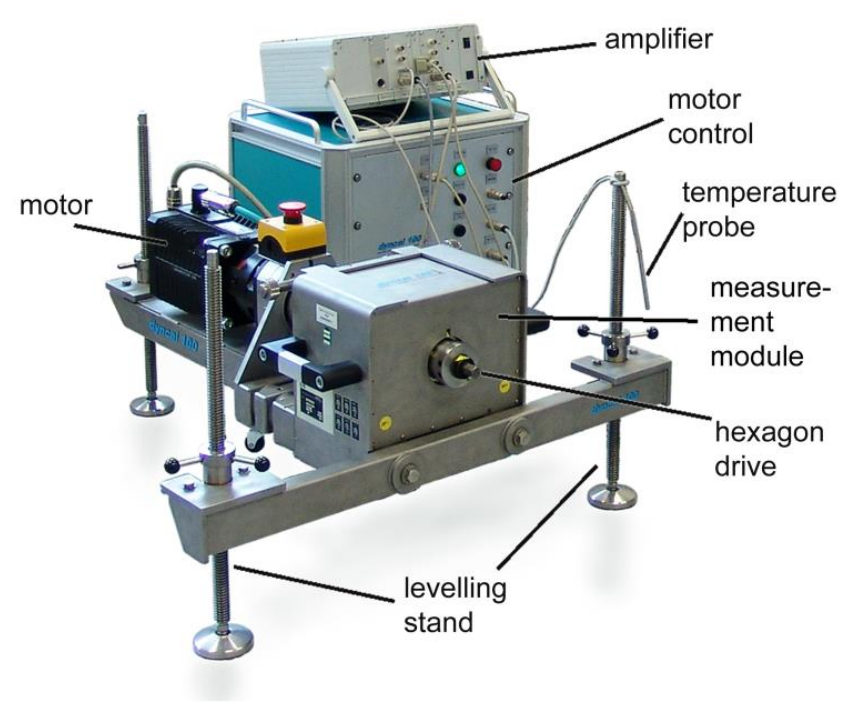

Figure 4. National standard for rotatory power measurement.

reference standards and the testing devices to the national standard, the national standard must be suited to both modes of operation. Furthermore, the national standard should be composed of modules so that it can be disassembled into transportable units for in-situ calibrations.

In accordance with the DIN VDE standard, the working range of medical ergometers spans a range of powers from $25 \mathrm{~W}$ to $400 \mathrm{~W}$ and a range of revolution speeds from $40 \mathrm{~min}^{-1}$ to $100 \mathrm{~min}^{-1}$. In this range, the ergometer must be able to regulate the set power in a sufficiently stable manner, even if the revolution speed is fluctuating. For special applications, such as in sports medicine, there are ergometers which have a considerably extended working range. The national standard should therefore have a working range with powers from $5 \mathrm{~W}$ to $1,000 \mathrm{~W}$ and revolution speeds from $5 \mathrm{~min}^{-1}$ to $150 \mathrm{~min}^{-1}$ (Figure 2). Combinations of high revolution with low power lead to low torque values. Values smaller than $0.5 \mathrm{~N} \cdot \mathrm{m}$ are not typical for medical applications and difficult to handle in breaking mode. Therefore, the specification in Figure 2 is restricted in the upper left corner.

At the lower end of the revolution speed working range, the national standard is in the torque limitation (Figure 2, black line). Here, the minimum attainable revolution speed is determined by the nominal torque limit of $75 \mathrm{~N} \cdot \mathrm{m}$ (Figure 3 , green line). Compliance with this limit is ensured within the control oscillations via an adjustable safety clutch and an electronic overload cut-off.

\section{DESCRIPTION OF THE STANDARD}

The national standard for rotatory power measurement [12] consists of the measurement module, a motor control with a drive unit, and an amplifier (Figure 4).

The measurement module contains the sensors used to obtain the measuring signals for the torque, the revolution speed, and the temperature of the torque sensor. An external probe delivers the temperature of the ambient air. The motor control complies with the electric requirements of the measuring facility to generate the revolution speed and the power at the driveshaft constantly enough according to the settings determined by the operator. To this end, the control unit contains microcontrollers, a power regulator, a load resistor, and safety circuits.

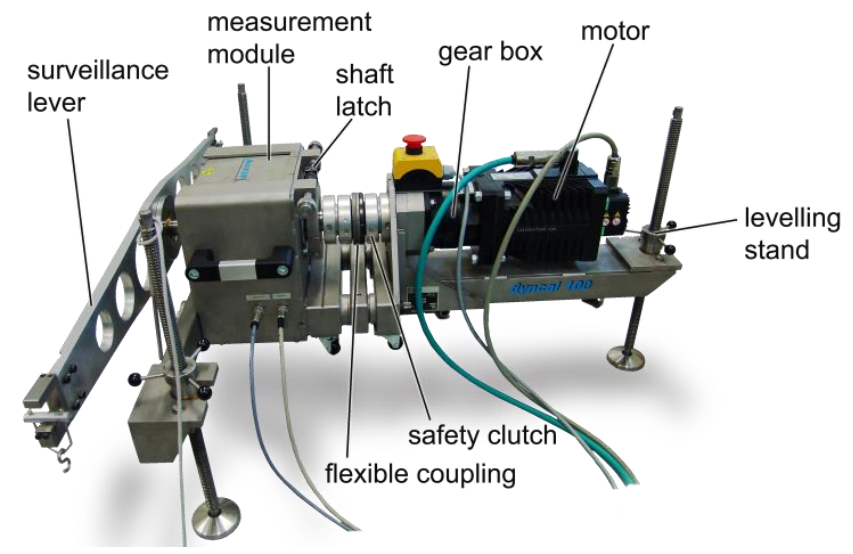

Figure 5. Measuring facility of the national standard for rotatory power. In the configuration shown, a balance beam is located at the torque measuring drive shaft for monitoring measurement purposes.

The measuring facility is driven by a brushless AC servomotor with an incremental encoder providing 4,096 pulses per revolution. The driveshaft is connected with the measurement module via a single-stepped, under-driven (at a 10:1 ratio) planetary gear train, a flexible coupling, and an adjustable safety clutch (Figure 5).

The measurement module includes a torque measuring flange with a nominal torque of $100 \mathrm{~N} \cdot \mathrm{m}$. The frequency-modulated torque signals of this flange can be read out contact-free. Furthermore, the module comprises a slit coupler, a transmittedlight encoding disc with 360 divisions per revolution, and a noncontact infrared temperature sensor.

On the driving side of the measuring module, an adapter that is suited to the task can be clamped centrically using a hydraulic chuck. Usually, the connection between the swivelling axes of an ergometer and of a testing device is established during the metrological check via a hexagonal telescopic bar. For that reason, an adapter with a hexagon head was chosen also for establishing the traceability between the national standard and the reference standard. For other tasks, such as monitoring measurements with a surveillance lever, a flat shaft end is needed as an output adapter.

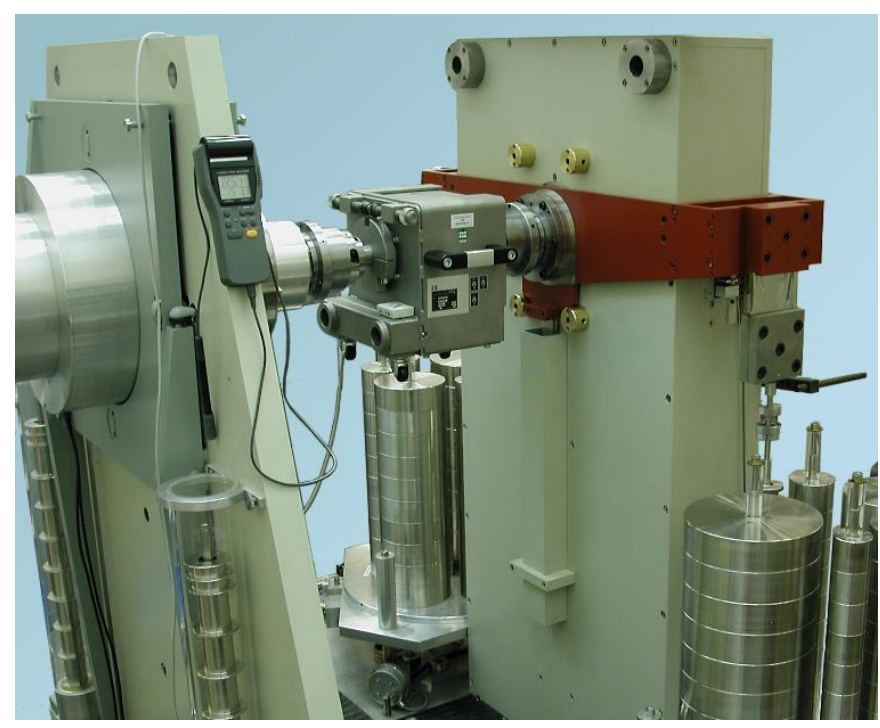

Figure 6. Mounting of the separate measurement module into a national torque standard machine of PTB for static torque calibration. 
All components of the measuring facility are mounted onto a frame in such a way that they can easily be disassembled for transport when in-situ measurements have to be carried out. Furthermore, this opens up the possibility of mounting the measurement module separately into a torque standard machine in order to establish the traceability of the torque flange (Figure 6).

By means of the three levelling stands, the frame can be adapted to the different installation heights of the calibration objects, and horizontal positioning of the measuring axis can be set.

\section{MEASURING PRINCIPLES}

\subsection{Measurement of the revolution speed}

The revolution speed $n$ in $\min ^{-1}$ is measured optically by means of an encoding disc that is mounted on the driveshaft in the measurement module. This disc supplies 360 pulses per revolution, i.e. a square-wave signal $S_{n}$ is generated with the frequency

$$
f_{\mathrm{n}}=\frac{360}{60 \frac{\mathrm{s}}{\min }} n
$$

With a revolution speed of $120 \mathrm{~min}^{-1}, f_{\mathrm{n}}$ yields $720 \mathrm{~Hz}$. A counter, $Z_{n}$, which is integrated in the amplifier, is armed by the rising edge of the revolution speed signal $\mathrm{S}_{\mathrm{n}}$ (Figure $7, t_{1}$ ).

With the next rising edge of the reference pulse $S_{\text {Ref }}$ with the frequency $f_{\text {Ref }}=32 \mathrm{MHz}$, the counter reading is transmitted to a memory (Figure $7, t_{2}$ ). The next rising edge of $S_{\text {Ref }}$ starts the counter with the value ' 1 ' (Figure $7, t_{3}$ ). From then on, the rising edges of the counting pulse $\mathrm{S}_{\mathrm{Zn}}$ with the frequency $f_{\mathrm{Zn}}=8 \mathrm{MHz}$ are counted and archived in the counting result $p\left(\mathrm{Z}_{\mathrm{n}}\right)$.

After a period of the revolution speed signal $S_{n}$, the counter is, in turn, armed by the rising edge without influencing the running count (Figure $7, t_{4}$ ). Hereupon, the next rising edge of the reference pulse causes the current counter reading to be transmitted to the memory (Figure $7, t_{5}$ ).

The uncertainty of this triggering amounts to a maximum of one reference pulse at the beginning and one at the end of the counting process, as well as to a maximum of one counting pulse during the counting. The total uncertainty of the period interval measurement thus amounts to

$$
u_{\mathrm{Pd}}=\frac{2}{32 \mathrm{MHz}}+\frac{1}{8 \mathrm{MHz}}=1.875 \cdot 10^{-7} \mathrm{~s}
$$

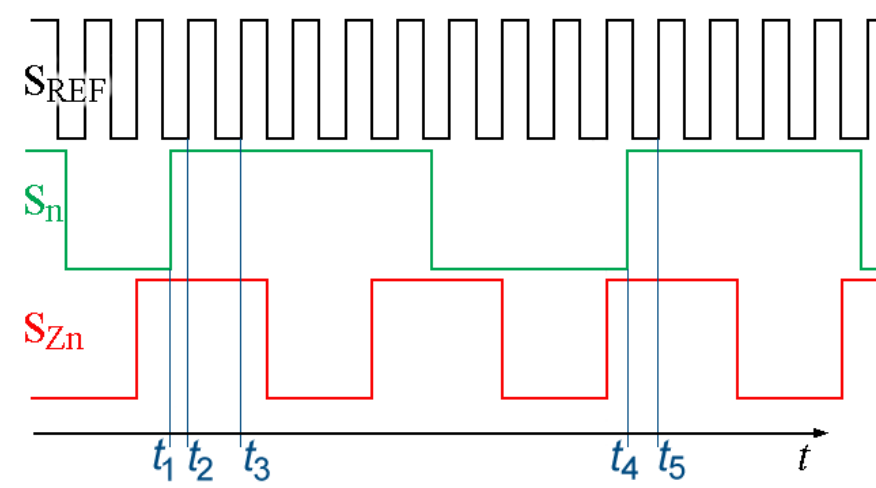

Figure 7. Triggering of the counting process for the measurement of the revolution speed (according to [12]).
The largest relative uncertainty of the period interval measurement $w_{\mathrm{Pd}}$ is obtained at the highest revolution speed of $150 \mathrm{~min}^{-1} \quad\left(f_{\mathrm{n}}=900 \mathrm{~Hz}\right)$. The relative uncertainty of an instantaneous period interval measurement thus amounts to

$$
\begin{aligned}
w_{\text {Pd,e }} & =1.875 \cdot 10^{-7} \mathrm{~s} \cdot 900 \mathrm{~Hz} \\
& =1.688 \cdot 10^{-4}
\end{aligned}
$$

whereby the uncertainty of the reference pulse was neglected. For an averaging depth $m$ of six periods and the assumption of a normal distribution, the uncertainty contribution of the averaged period interval measurement amounts to

$$
w_{\mathrm{Pd}, \mathrm{m} 6}=\frac{w_{\mathrm{Pd}, \mathrm{e}}}{\sqrt{6 \cdot 360}}=3.6 \cdot 10^{-6} .
$$

Based on each measured value for the period interval, the controller computes the instantaneous revolution speed $n_{\mathrm{e}}$ with a resolution of 32 bits, which is then, with a resolution of $0.005 \mathrm{~min}^{-1}$, sent to the computer for further analysis. This takes place 360 times per revolution. The highest relative contribution of the revolution speed resolution to the measurement uncertainty $w_{\mathrm{rn}}$ of the revolution speed mean value lies at $n=5 \mathrm{~min}^{-1}$ and amounts, for an averaging depth $m$ of six periods, to

$$
w_{\text {rn6 }}=\frac{0.005 \min ^{-1}}{5 \min ^{-1} \cdot \sqrt{6 \cdot 360}}=2.2 \cdot 10^{-5}
$$

The errors of the slots due to the limited resolution of their lithographic manufacturing of $1 \cdot 10^{-3} \mathrm{~mm}$ led to a relative error of the slit edges of $1.15 \cdot 10^{-3}$ and, together with the number of pulses per six revolutions (2160), to a mean relative jitter error $w_{\mathrm{ej}}$ of $2.47 \cdot 10^{-5}$.

The analysis of the relative contribution to the mean value of the period interval and of the revolution speed merely serves as orientation regarding the required relative measurement uncertainty for the revolution speed measurement. With $1 \cdot 10^{-3}$, the required relative uncertainty is larger by a factor of more than 40 than the contribution of (5). In the case of the standard, averaging starts at the level of the instantaneous powers. The estimation above shows, however, that the resolution of the revolution speed values is sufficient for fulfilling the requirements placed on the standard.

The instantaneous revolution speed $n_{\mathrm{e}}$ in $\min ^{-1}$ is obtained from the counting result $p\left(Z_{n}\right)$ and the counting pulse frequency $f_{\mathrm{Zn}}$ and yields:

$$
n_{\mathrm{e}}=\frac{60 \cdot f_{\mathrm{Zn}}}{360 \cdot p\left(\mathrm{Z}_{\mathrm{n}}\right)}
$$

\subsection{Torque measurement}

\subsubsection{Rotatory torque measurement}

In this way, a rising edge of the revolution speed pulse $S_{n}$ arms the torque counter $Z_{\mathrm{P}}$, which determines the period interval of the torque signal in periods of the counting pulse $S_{Z M}$ (Figure $8, t_{1}$ ). The following rising edge of the torque signal $S_{M}$ starts this counter (Figure $8, t_{2}$ ). After the revolution speed counter $Z_{\mathrm{n}}$ (Figure 8, $t_{3}$ ) has stopped, the next rising edge of the torque signal $S_{M}$ ends the counting process of $Z_{\mathrm{P}}$ (Figure $8, t_{4}$ ). At the same time as $Z_{\mathrm{P}}$, the counter $Z_{\mathrm{M}}$, which counts the number of periods of the torque signal $S_{M}$ that lie within the gate time of $Z_{\mathrm{n}}$ and $Z_{\mathrm{P}}$, is triggered. 


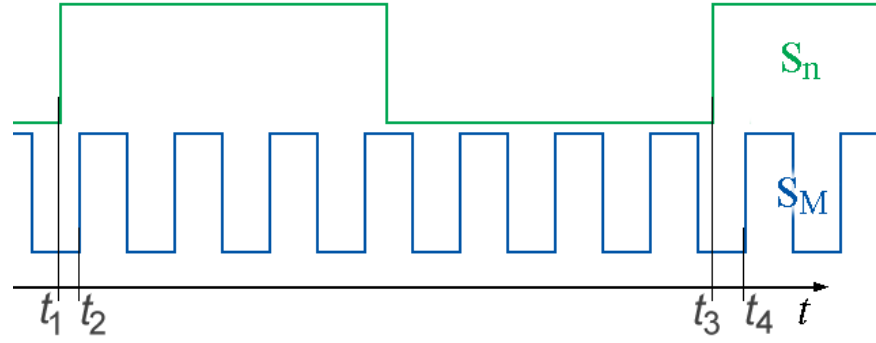

Figure 8. Triggering of the counting process for the measurement of the torque (according to [12]).

Since arming the counter takes place at the same time as the rising edge of the revolution speed signal, the beginning and end of the counting processes for the revolution speed and the torque differ from each other by a maximum of one period interval of the torque signal. Thus, the uncertainty is obtained from the difference between the gate time focuses for the two measurements as:

$$
u_{\mathrm{Tz}}=\frac{1}{f_{\mathrm{M}}} \text {. }
$$

Depending on the applied torque, due to the frequency modulation of the torque signal, the value of $u_{\mathrm{TZ}}$ oscillates between $2 \cdot 10^{-4} \mathrm{~s}$ at the $100 \mathrm{~N} \cdot \mathrm{m}$ left-hand torque and $7 \cdot 10^{-5} \mathrm{~s}$ at the $100 \mathrm{~N} \cdot \mathrm{m}$ right-hand torque. This still does not make the actual influence of this uncertainty in the result of the power determination accessible, because it depends on the dynamic evolution of the revolution speed and of the torque within the gate time of the counters. However, one can conclude that variations of the revolution speed and of the torque with frequencies below $500 \mathrm{~Hz}$ - i.e. one tenth of the smallest occurring frequency of the torque signal - can still be reliably resolved by the measuring system. This is 200 times the upper revolution speed limit and is - also in view of the mass inertias which are involved in the rotation - sufficient for imaging the dynamic system.

The instantaneous frequency of the torque signal $f_{\mathrm{Me}}$, which is assigned to the current torque, is obtained from the counting results $p\left(\mathrm{Z}_{\mathrm{P}}\right)$ and $p\left(\mathrm{Z}_{\mathrm{M}}\right)$ as well as from the counting pulse $f_{\mathrm{ZM}}$, and it yields:

$$
f_{\mathrm{Me}}=\frac{p\left(\mathrm{Z}_{\mathrm{M}}\right)}{p\left(\mathrm{Z}_{\mathrm{P}}\right)} f_{\mathrm{ZM}} \text {. }
$$

The counting uncertainty of $p\left(Z_{\mathrm{P}}\right)$ has the most unfavourable influence at the minimum frequency of the torque signal and at the maximum revolution speed i.e. at $f_{M}=5 \mathrm{kHz}$ and $n=150 \mathrm{~min}^{-1}$. Then, the frequency ratio between $f_{\mathrm{M}}$ and $f_{\mathrm{n}}$ only amounts to 5.55 . When the phase angle is unfavourable, only four full periods of $\mathrm{S}_{\mathrm{M}}(5 \mathrm{kHz})$ then fit into the gate time shown in Figure 8. In this case, there is a counting error of one pulse of $p\left(Z_{\mathrm{P}}\right)$. On the other hand, the mean counting result amounts to 25,600 pulses (four periods of $5 \mathrm{kHz}$ need $0.8 \mathrm{~s}$ of time; in this time, $0.8 \mathrm{~s} \cdot 32 \mathrm{MHz}$ pulses are counted). The relative contribution of the counting error of $p\left(Z_{\mathrm{P}}\right)$ to the measurement uncertainty of the instantaneous torque measurement thus amounts to

$$
w_{\mathrm{ZPe}}=\frac{1}{25600}=3.9 \cdot 10^{-5} \text {. }
$$

At an averaging depth of six revolution periods, this results in a relative uncertainty contribution of

$$
w_{\mathrm{ZPm}}=\frac{3.9 \cdot 10^{-5}}{\sqrt{6 \cdot 360}}=8 \cdot 10^{-7} \text {. }
$$

The controller computes the instantaneous torque from the values of $f_{\mathrm{Me}}$, taking the zero-point signal of the torque sensor of $10 \mathrm{kHz}$ and its sensitivity of $5 \mathrm{kHz} / 100 \mathrm{~N} \cdot \mathrm{m}$ into account, according to

$$
M_{\mathrm{e}}=\frac{f_{\mathrm{Me}}-10 \mathrm{kHz}}{5 \mathrm{kHz}} 100 \mathrm{~N} \cdot \mathrm{m}
$$

with a resolution of $1 / 325 \mathrm{~N} \cdot \mathrm{m}$. At the most unfavourable torque value of the working range of $0.48 \mathrm{~N} \cdot \mathrm{m}$ $\left(P=5 \mathrm{~W}, n=100 \mathrm{~min}^{-1}\right)$, this resolution corresponds to a relative uncertainty contribution of $6.4 \cdot 10^{-3}$. By averaging over six revolution periods, the relative contribution is reduced to $w_{\mathrm{rMm}}=1.4 \cdot 10^{-4}$.

In contrast to speed measurements, a jitter error here does not also result from mechanical manufacturing tolerances; rather, it exclusively comes from electrical signal distortions, for which an upper estimate was found by equating them with $w_{\mathrm{ej}}$.

\subsubsection{Static torque measurement}

In certain cases, it makes sense to also measure the torque applied to the sensor without rotation. This is, for example, the case if a weighing beam is mounted on the sensor output to establish the traceability of the torque sensor with direct-load masses (Figure 5). The counters $Z_{\mathrm{P}}$ and $Z_{\mathrm{M}}$ can then be armed directly by the rising edges of the torque signal $S_{\mathrm{M}}$. The control surface of the standard allows such measurements with averaging depths $m$ of 128 or 512 periods of $\mathrm{S}_{\mathrm{M}}$. In accordance with Equations (8) and (11), static torque values $M_{\mathrm{s}}$ are calculated from the counting results. These are not instantaneous values as in the case of a rotation; rather, they are values that are averaged over a period of time that is obtained from the mean torqueequivalent frequency of $\mathrm{S}_{\mathrm{M}}$ and the averaging depth.

Analogous to Equation (2), the triggering error of the torque counting which has to be taken into account yields, in the most unfavourable case of $f_{\mathrm{M}}=15 \mathrm{kHz}$ and $m=128$, a contribution to the uncertainty of the static torque of $w_{\mathrm{ZsMm}}=3 \cdot 10^{-6}$. Analogous to the previous section, the resolution, with $m=128$, has a relative uncertainty contribution of $w_{\mathrm{rs}}=5.7 \cdot 10^{-4}$. For $m=512$, uncertainty contributions are yielded, which amount to $w_{\mathrm{ZsMm}}=1.4 \cdot 10^{-6}$ and $w_{\mathrm{rs}}=2.8 \cdot 10^{-4}$.

\subsubsection{Corrections}

Prior to further use, systematic errors must be eliminated from the uncorrected torque values $M\left(M_{\mathrm{e}}\right.$ and $M_{\mathrm{m}}$, respectively).

When in operation, the standard for rotatory power generates a considerable amount of heat. Despite the thermal decoupling between the motor module and the sensor module, this leads to temperature increases of a few $\mathrm{K}$ during calibration. Typical relative temperature coefficients of the torque sensor used lie around $1 \cdot 10^{-5} / \mathrm{K}$. This allows for the contribution of usual temperature increases of up to $5 \mathrm{~K}$ to the relative measurement uncertainty to be estimated as $w_{\mathrm{TM}}=1.4 \cdot 10^{-5}$ and the correction measures to be discarded.

The temperature coefficient of the torque sensor zero signal usually lies clearly higher than that of the sensitivity, such that a correction must be performed. This is achieved by loosening the 
mechanical connection to the calibration object at appropriate locations during the calibration in order to determine the current idle torque $M_{0, \text { rot }}$ with the sensor output open and at medium revolution speed. This value is then used to correct the raw values $M$ according to

$$
M_{\mathrm{korr} 1}=\left(M-M_{0, \text { rot }}\right) E_{\mathrm{korr}}
$$

thereby applying a correction value $E_{\text {korr }}$ for the drift of the signal processing of the torque sensor. The correction value $E_{\text {korr }}$ is determined by means of intermediate electric tests using the internal calibration signal of the torque sensor.

The characteristic curves of the torque sensors include nonlinearities that may lead to relative errors of typically a few $10^{-4}$. While tracing back the torque sensor used in the standard, these linearity errors are documented as a third-order polynomial for the right-hand torque branch and one for the left-hand torque branch of the characteristic curve, and the linearity errors are archived in the control program of the standard. When correcting the linearity errors, this polynomial is applied to each torque value:

$$
M_{\mathrm{korr} 2}=a_{1} M_{\mathrm{korr} 1}+a_{2} M_{\mathrm{korr} 1}^{2}+a_{3} M_{\mathrm{korr} 1}^{3},
$$

with the cubic coefficients $a_{\mathrm{x}}(\mathrm{x}=\{1,2,3\})$ for the left-hand as well as for the right-hand torque. The hysteresis of the torque sensor is not included in the cubic polynomial and leads to a relative contribution of $w_{\mathrm{HyM}}=4.3 \cdot 10^{-4}$ to the measurement uncertainty of the torque.

\subsection{Power determination}

When the DIN VDE standard is operated, variations in the revolution speed occur due to instabilities in the feedback control of both the standard and the calibration object. In combination with the inertia torques of the rotating masses, this results in elastic vibrations, which either reduce or add to the system's idle power.

The instantaneous values of the revolution speed and of the torque are obtained during periods of time that are short compared to the oscillation periods of the idle power. They enable the calculation of instantaneous values of the power, which are able to temporally resolve the idle powers. In this way, the measured values of the active power of the rotating system are available, which are necessary for assessing the control behaviour of the calibration objects.

The instantaneous rotatory power $P_{\mathrm{e}}$ is defined as the product of the instantaneous values of the torque $M_{\mathrm{e}}$ and of the angular velocity $\omega_{\mathrm{e}}$. Based on the values of $n_{\mathrm{e}}$ and $M_{\mathrm{korr}}$, which are provided by the controller, the control program computes 360 individual values of the instantaneous power per revolution

$$
P_{\mathrm{e}}=\omega_{\mathrm{e}} M_{\mathrm{korr} 2}=\frac{2 \pi}{60} n_{\mathrm{e}} M_{\mathrm{korr} 2}
$$

which are made available as a timing diagram for the analysis of the control behaviour and are saved in a database.

For the total work in the averaging interval, which - with Equations (11), (12) and (13) - yields

$$
A_{\mathrm{m}}=\sum_{i=1}^{m \cdot 360} \frac{2 \pi}{360} M_{\mathrm{korr} 2, i}
$$

and with the duration of this interval, which is yielded with Equation (6),

$$
t_{\mathrm{m}}=\sum_{i=1}^{m \cdot 360} \frac{60}{360} \frac{1}{n_{\mathrm{e}, i}}
$$

the averaged power is calculated for an averaging depth $m$

$$
P_{\mathrm{m}}=\frac{A_{\mathrm{m}}}{t_{\mathrm{m}}}
$$

which can be selected in the control program. Since significant components of the power variations correlate with the revolution speed of the measuring axis [10], these power variations can, for the most part, be averaged out by averaging over the complete revolutions of the measuring axes. In practical application, an averaging depth of $m=6$ is typically used. This averaging depth is a compromise between a low measurement uncertainty and an appropriate time expenditure. In the case of traceability measurements, much larger averaging depths are usually selected in order to reduce, for example, the influence of the resolution of the signal processing on the measurement uncertainty.

\section{REGULATION}

Depending on the purpose of use, the standard must be able to work either as a brake or as a drive.

In speed-regulated operation, the operator can pre-select a revolution speed that is maintained as stable by the standard within the limits of the control parameters - against the variable braking torque of the calibration object. In this case, the standard operates in driving mode.

In braking mode, the standard maintains a pre-defined torque or a pre-defined power by varying the braking torque against the variable revolution speed of the calibration object.

Due to the masses involved, both modes of operation can only realise the settling times in the range of a few seconds. This agrees well with the intention of the application, since fast variations in the revolution speed or in the torque of the ergometers must categorically be prevented for the patient's safety. Observance of appropriate waiting times after a change in the parameters before starting a measurement sequence is therefore an integral part of the calibration rules.

\section{TRACEABILITY OF THE NATIONAL STANDARD}

Since the realisation of the rotatory power measurement by means of the national standard presented here is not directly based on absolute quantities, the composed quantity must be traced back via the respective national standards of the individual quantities i.e. along five different paths (Figure 9).

The relative measurement uncertainties that are to be assigned to these paths are taken from the Ishikawa diagram as shown in Section 7 (Figure 11) and from the indications given in Table 1 and Table 2.

With the aid of transfer standards and auxiliary devices, the partial quantities 'revolution speed' and 'torque' can be traced back both statically and rotatorily. Hereby, 'statically' means a measurement in which the measuring axis of the standard does not perform a rotation, whereas 'rotatorily' designates measurements where the measuring axis of the standard rotates. As described in section 4.2, the metrological difference between these two cases resides in the type of triggering. Furthermore, static measurements can elucidate the properties of the amplifier separately to the interference values of the drive and of the 


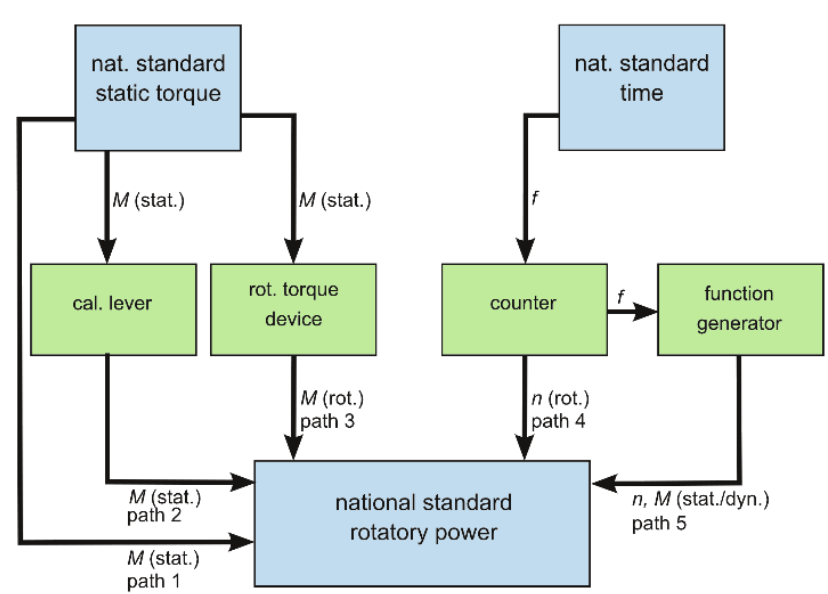

Figure 9. Traceability of the national standard for rotatory power measurement to the national standards for time and static torque. There are five different traceability paths.

sensors, while the rotatory measurements shed light on the behaviour of the system as a whole.

Dynamic traceability can be attained without the rotation of the measuring axis. Rather, it is attained by feeding simulated revolution speed signals into the amplifier, exploiting the triggering that is intended for rotatory operation.

\subsection{Traceability of the revolution speed}

The revolution speed is traced back to the national standard of time by means of a counter, which serves as a transfer standard (Tf) for the reference frequency $f_{\mathrm{R}}$ of $10 \mathrm{MHz}$.

The measuring amplifier is equipped with an input and an output for the revolution speed signal $S_{n}$ by means of which external TTL signals can be fed into the measured value acquisition unit, and the signals from the encoded disk can be tapped without influencing their measurement in the amplifier.

\subsubsection{Dynamic traceability of the revolution speed}

With the aid of a function generator, a TTL signal is applied to the revolution speed input of the amplifier. The frequencies of this signal correspond to those provided by the encoded disk in the working range of the standard (Figure 9, path 5). The revolution speed indication of the standard is compared with the fed-in frequency, which is determined by means of the abovementioned counter. The simultaneity of the two measurements is ensured by external triggering of both the amplifier and the counter.

\subsubsection{Rotatory traceability of the revolution speed}

Here, instead of comparing the measurements of external signals generated by a function generator, the signals of the encoded disk are used. For this purpose, the measuring axis of the standard is caused to rotate without load. The internal triggering signal of the slit coupler is used to synchronise the amplifier and the counter (Figure 9, path 4).

These measurements can also be carried out with tolerable effort as intermediate tests of the revolution speed measurement.

\subsection{Torque traceability}

\subsubsection{Static torque traceability}

The measuring module is decoupled from the rest of the standard and is mounted into the measuring axis of PTB's national standard for static torque, the $1-\mathrm{kN} \cdot \mathrm{m}-\mathrm{Dm}$ standard facility (Figure 6). There, the torque sensor can be calibrated statically i.e. as a temporally stable load in accordance with DIN 51309 [13] (Figure 9, path 1). As a result of this calibration, three coefficients are calculated for the cubic correction of the linearity error of the torque sensor for left-hand as well as for right-hand torque. These coefficients are then archived in the control program of the standard. A second, subsequent calibration using these updated coefficients provides the torque indication errors of the standard, which are included in the relative measurement uncertainty of the static traceability WRMs.

A static electric stability measurement of the torque is carried out in the sensor module when $E_{\text {korr }}$ is determined by means of an internal calibration signal. Since here, only relative changes compared to a reference value are analysed, this is not a traceability process, and it is therefore not included in Figure 9.

\subsubsection{Rotatory torque traceability}

Since there is no national standard for rotatory torque traceability, traceability of this quantity can only be established via special investigations (Figure 9, path 3). A PTB report [14] demonstrates that the relative influence $w_{\mathrm{RMr}}$ of the angular velocity on the sensitivity of the standard's torque sensor from $8 \mathrm{~N} \cdot \mathrm{m}$ to $100 \mathrm{~N} \cdot \mathrm{m}$ is smaller than $5.1 \cdot 10^{-4}$ at revolution speeds up to $600 \mathrm{~min}^{-1}$. The facility that was developed for this investigation (the RTD, Figure 10) consists of a machine frame in which the torque sensor to be tested is mounted between two drives which, during rotation, apply a torque to the sensor via phase-shifted operation. This torque can then be measured as a reaction torque, using a reference transducer installed at the bottom of the machine.

Influences that can directly be attributed to the rotation (e.g. due to centripetal forces) can thus be estimated with $w_{\mathrm{RMr}}$ in the measurement uncertainty analysis. Other effects of the rotation that can increase the uncertainty of the static traceability of the

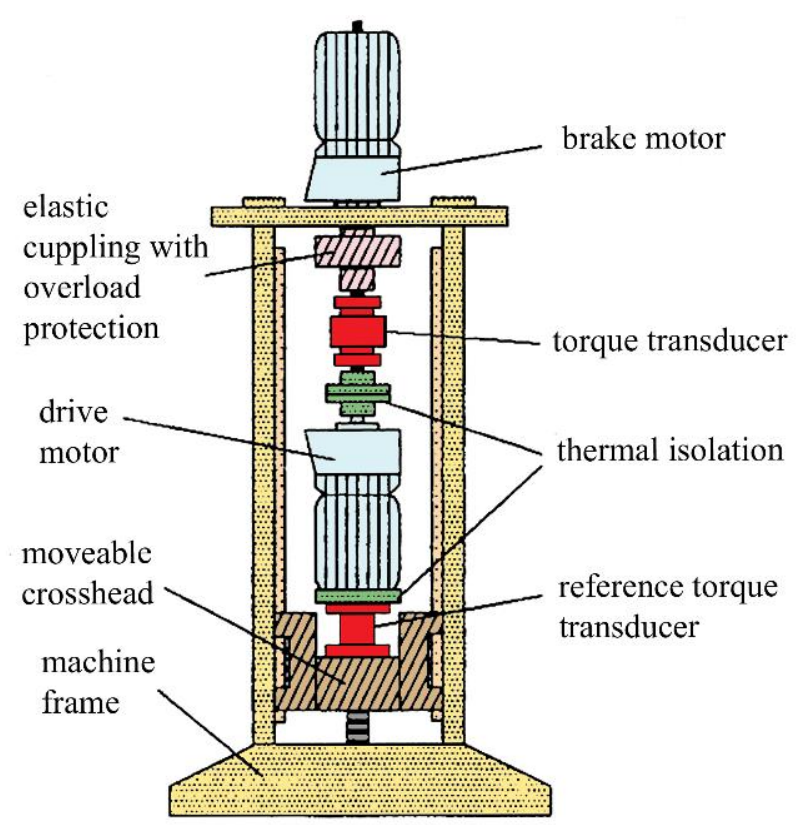

Figure 10. Rotational torque device (RTD). Facility for the determination of the influence of rotation on the sensitivity of the reference torque transducer of the national standard [14]. 
torque measurement (such as friction and vibrations) can be eliminated in the first approximation by zero correction (12).

\subsubsection{Dynamic torque traceability}

TTL signals are applied to the inputs of the amplifier using a function generator. These signals simulate both the revolution speed output and the torque output of the sensor module. The torque indication of the standard is compared with the torque that is equivalent to the simulated frequency fed in, which is, in turn, measured by the transfer counter (Figure 9, path 5). This allows the triggering and the data processing in the controller to be traced back independently of the mechanical generation of torques in the drive.

\subsubsection{Static intermediate testing of the torque measurement}

Static torques can be applied to the rotation-protected measuring module using a facility consisting of a balance beam and load masses (Figure 5). At PTB's torque calibration facilities, this device can be linked with the national standard for static torque (Figure 9, path 2). In this way, stability tests of the torque measurement can be carried out between the regular link-ups of the static torque according to Figure 9, path 1, without having to remove the measuring module.

\section{MEASUREMENT UNCERTAINTIES}

When determining the measurement uncertainty for the rotatory power measurement by means of the national standard, the contributions of the counters involved in the measurement; the static and of the rotatory traceability of the torque; and various application-related quantities must be taken into account (Figure 11). Among the latter, the systematic indication errors of the measuring instruments are of particular importance.

Some of the contributions must be taken into account several times. The transfer counter enters, for example, into the rotatory traceability of the revolution speed and into the dynamic traceability of the torque. Furthermore, the contributions of the counter $Z_{\mathrm{P}}$ to the torque determination enter both into the dynamic traceability and into the determination of $E_{\text {korr }}$ and $M_{0, \text { rot. }}$

The relative combined measurement uncertainty for the determination of the rotatory power consists of the relative measurement uncertainties for the revolution speed and for the

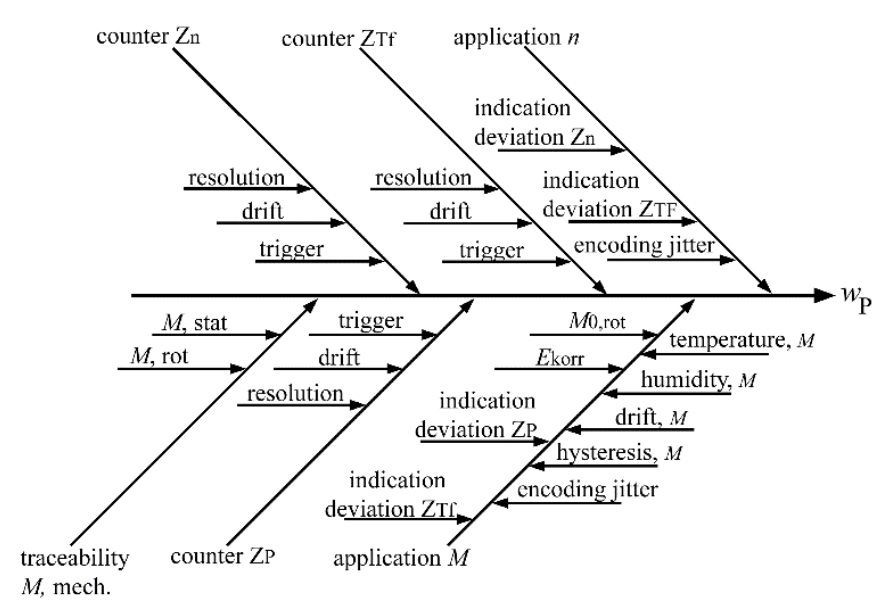

Figure 11. Ishikawa diagram for the contributions to the measurement uncertainty of the rotatory power in PTB's national standard.
Table 1. Relative standard measurement uncertainties as contributions to the relative total measurement uncertainty. The index indicates the percentage of contributions to the sum of squared uncertainties, which are weighted with their respective multiple occurrences in the combined uncertainty.

\begin{tabular}{|c|c|c|c|}
\hline Contribution & $\begin{array}{l}\text { Probability } \\
\text { distribution }\end{array}$ & Value & $\begin{array}{l}\text { Index in } \\
\%\end{array}$ \\
\hline$w_{\mathrm{RMr}}$ & Normal & $2.55 \cdot 10^{-4}$ & 38.42 \\
\hline$w_{\mathrm{RMs}}$ & Normal & $1.70 \cdot 10^{-4}$ & 17.08 \\
\hline$w_{\mathrm{HyM}}$ & Rectangle & $1.60 \cdot 10^{-4}$ & 15.13 \\
\hline$w_{\mathrm{FM}}$ & Rectangle & $1.44 \cdot 10^{-4}$ & 12.31 \\
\hline$w_{\mathrm{rMm} 6}(0.48 \mathrm{~N} \cdot \mathrm{m})$ & Rectangle & $1.38 \cdot 10^{-4}$ & 11.24 \\
\hline$w_{\mathrm{rMm} 60}(0.48 \mathrm{~N} \cdot \mathrm{m})$ & Rectangle & $4.36 \cdot 10^{-5}$ & 3.37 \\
\hline$w_{\text {Anr }}\left(150 \mathrm{~min}^{-1}\right)$ & Rectangle & $4.02 \cdot 10^{-5}$ & 0.96 \\
\hline$w_{\mathrm{ej}}$ & Normal & $2.47 \cdot 10^{-5}$ & 0.72 \\
\hline$w_{\mathrm{rn} 6}\left(150 \mathrm{~min}^{-1}\right)$ & Normal & $2.20 \cdot 10^{-5}$ & 0.29 \\
\hline$w_{\mathrm{AMd}}$ & Normal & $1.90 \cdot 10^{-5}$ & 0.21 \\
\hline$w_{\mathrm{TM}}$ & Rectangle & $1.44 \cdot 10^{-5}$ & 0.12 \\
\hline$w_{\mathrm{DM}}$ & Rectangle & $1.00 \cdot 10^{-5}$ & 0.12 \\
\hline$w_{\text {Tn }}$ & Rectangle & $3.00 \cdot 10^{-6}$ & 0.02 \\
\hline$w_{\mathrm{Pd}, \mathrm{m} 6}\left(150 \mathrm{~min}^{-1}\right)$ & Rectangle & $3.63 \cdot 10^{-6}$ & 0.00 \\
\hline$w_{\mathrm{tTZ}}$ & Rectangle & $1.75 \cdot 10^{-6}$ & 0.00 \\
\hline$w_{\text {Pd,m60 }}\left(150 \mathrm{~min}^{-1}\right)$ & Rectangle & $1.15 \cdot 10^{-6}$ & 0.00 \\
\hline$w_{\mathrm{ZPm} 6}$ & Normal & $8.40 \cdot 10^{-7}$ & 0.00 \\
\hline$w_{\mathrm{DZ}}$ & Rectangle & $2.89 \cdot 10^{-7}$ & 0.00 \\
\hline$w_{\mathrm{ZPm} 60}$ & Normal & $2.66 \cdot 10^{-7}$ & 0.00 \\
\hline$w_{\mathrm{ATZ}}$ & Rectangle & $2.89 \cdot 10^{-7}$ & 0.00 \\
\hline$w_{\mathrm{rn} 60}\left(150 \mathrm{~min}^{-1}\right)$ & Normal & $2.27 \cdot 10^{-7}$ & 0.00 \\
\hline$w_{\mathrm{rZ}}$ & Rectangle & $1.00 \cdot 10^{-7}$ & 0.00 \\
\hline$w_{\mathrm{TZ}}$ & Normal & $1.00 \cdot 10^{-8}$ & 0.00 \\
\hline
\end{tabular}

torque, each of which is, in turn, sub-divided and can thus be traced back to the relative standard measurement uncertainties indicated in Table 1 as numerical values for the upper estimations of the contributions to the best measurement capability. Hence, these are estimations in case an ideal calibration object is used in which, for instance, no feedback of the control oscillations to the standard need to be taken into account.

The model function of the uncertainty budget is given according to Equation (14) by Equation (18):

$$
P_{\mathrm{e}}=\frac{2 \pi}{60} n M(1-\Delta n)(1-\Delta M)
$$

with

$$
\Delta n=\Delta Z_{\mathrm{n}}+\Delta Z_{\mathrm{TF}, \mathrm{n}}+\Delta n_{\mathrm{appl}}
$$

and

$$
\Delta M=\Delta M_{\mathrm{Tr}}+\Delta Z_{\mathrm{P}}+\Delta M_{\mathrm{appl}}+\Delta Z_{\mathrm{TF}, \mathrm{M}} .
$$

Furthermore, taking into account parameters $x$, which correspond to the contributions in Table 1 and are named according to the indices of these contributions, the following equations describe the compositions of $\Delta n$ and $\Delta M$ :

$$
\begin{aligned}
& \Delta Z_{\mathrm{n}}=\Delta x_{\mathrm{DZ}}+\Delta x_{\mathrm{Tn}}+\Delta x_{\mathrm{rn} 6}+\Delta x_{\mathrm{rn} 60}+\Delta x_{\mathrm{Pd}, \mathrm{m} 6} \\
& +\Delta x_{\mathrm{Pd}, \mathrm{m} 60} \\
& \Delta Z_{\mathrm{TF}, \mathrm{n}}=2 \Delta x_{\mathrm{Tn}}+2 \Delta x_{\mathrm{DZ}}+\Delta x_{\mathrm{tTZ}}+\Delta x_{\mathrm{rZ}}+\Delta x_{\mathrm{TZ}} \\
& \Delta n_{\mathrm{appl}}=\Delta x_{\mathrm{Anr}}+\Delta x_{\mathrm{ATZ}}+\Delta x_{\mathrm{ej}}
\end{aligned}
$$




$$
\Delta M_{\mathrm{Tr}}=\Delta x_{\mathrm{RMm}}=\Delta x_{\mathrm{RMs}}+\Delta x_{\mathrm{RMr}}
$$

$$
\Delta Z_{\mathrm{P}}=\Delta x_{\mathrm{ZPm} 6}+\Delta x_{\mathrm{ZPm} 60}+\Delta x_{\mathrm{DZ}}+\Delta x_{\mathrm{rMm} 6}+\Delta x_{\mathrm{rMm} 60}
$$

$$
\begin{aligned}
& \Delta M_{\mathrm{appl}} \\
& \quad=\Delta x_{\mathrm{AMd}}+\Delta x_{\mathrm{ej}}+2 \Delta x_{\mathrm{ZPm} 60}+\Delta x_{\mathrm{DZ}}+2 \Delta x_{\mathrm{rMm} 60} \\
& \quad+2 \Delta x_{\mathrm{DM}}+\Delta x_{\mathrm{FM}}+\Delta x_{\mathrm{TM}}+\Delta x_{\mathrm{MHy}}
\end{aligned}
$$

$$
\Delta Z_{\mathrm{TF}, \mathrm{M}}=2 \Delta x_{\mathrm{DZ}}+\Delta x_{\mathrm{rZ}}+\Delta x_{\mathrm{tTZ}}+\Delta x_{\mathrm{TZ}} .
$$

The relative combined measurement uncertainty for the revolution speed $w_{n}$ results according to Equation (19) from the contributions of the transfer counter $\mathrm{Z}_{\mathrm{Tf}}$, from the contributions of the revolution speed counter $Z_{n}$ in the standard, and from the contributions of the mechanical components $n_{\text {appl }}$ in the measuring module. Hereby, $w_{\mathrm{n}}$ yields, with the values from Table 1 and the symbols from Table 2:

$$
\begin{aligned}
w_{\mathrm{n}}= & \left|w_{\mathrm{Anr}}+w_{\mathrm{ATZ}}\right| \\
& +\left(\begin{array}{c}
3 \cdot w_{\mathrm{DZ}}^{2}+w_{\mathrm{Pd}, \mathrm{m} 6}^{2}+w_{\mathrm{Pd}, \mathrm{m} 60}^{2}+ \\
w_{\mathrm{rn} 6}^{2}+w_{\mathrm{rn} 60}^{2}+3 \cdot w_{\mathrm{Tn}}^{2}+ \\
w_{\mathrm{tTZ}}^{2}+w_{\mathrm{rZ}}^{2}+w_{\mathrm{TZ}}^{2}+w_{\mathrm{ej}}^{2}
\end{array}\right)^{1 / 2} \\
& =7.4 \cdot 10^{-5} .
\end{aligned}
$$

In terms of the contributions for the long-term drift $w_{\mathrm{DZ}}$ and for the temperature dependence $w_{\mathrm{Tn}}$, it is assumed that they are the same for both counters. Therefore, the respective measurement uncertainties enter twice for the traceability and once for the application. The relative indication errors of the two counters $w_{\text {Anr }}$ and $w_{\text {ATZ }}$ are systematic components and contribute to the uncertainty. The prevailing contributions are the relative revolution indication error of the standard $w_{\text {Anr }}$, the uncertainty of the period interval measurement $w_{\mathrm{Pd}, \mathrm{m}}$, and the resolution of the revolution speed values of the standard $w_{\mathrm{rn}}$. $w_{\mathrm{Pd}, \mathrm{m}}$ and $w_{\mathrm{rn}}$ are applied as a function of the selected revolution speed and of the averaging depth $m$. The values used here are the values at $n=150 \mathrm{~min}^{-1}$, which lead to the maximum value of $w_{\mathrm{n}}$. When the standard is used for calibrations, $m=6$ is selected in order to keep the time effort and the thermal load as low as possible. Here, the contributions $w_{\mathrm{Pm}, \mathrm{d} 6}$ and $w_{\mathrm{rn} 6}$ must be applied. In the case of traceability measurements, longer averaging makes sense (e.g. $m=60$ at $n=150 \mathrm{~min}^{-1}$ ), whose contributions are the relative uncertainties $w_{\mathrm{Pd}, \mathrm{m} 60}$ and $w_{\mathrm{rn} 60}$. In this context, the dynamic traceability of the revolution speed (Figure 9, path 5) has the character of an additional test of the processing of revolution speed signals and is not necessary for the complete link-up of the revolution speed measurement. It is therefore not taken into account in this measurement uncertainty budget. Since the counters are not in contact with the drive unit, the influence of the rise in temperature caused by the measuring operation is negligible.

The relative combined measurement uncertainty for the mechanical link-up of the torque $w_{\mathrm{RMm}}$ is obtained from the relative measurement uncertainty for the static torque traceability $w_{\mathrm{RMs}}$ and from the relative measurement uncertainty for the rotatory torque traceability $w_{\mathrm{RMr}}$ with the values from Table 1 and the symbols from Table 2 and yields

$$
w_{\mathrm{RMm}}=\sqrt{w_{\mathrm{RMs}}^{2}+w_{\mathrm{RMr}}^{2}}=3.1 \cdot 10^{-4} .
$$

The relative combined uncertainty of the measurement of the torque $w_{\mathrm{M}}$ yields - with (29), with the values from Table 1 and with the symbols from Table $2-$

$$
\begin{aligned}
w_{\mathrm{M}} & =\left|w_{\mathrm{AMd}}+w_{\mathrm{ATZ}}\right| \\
& +\left(\begin{array}{c}
w_{\mathrm{RMm}}^{2}+w_{\mathrm{ZPm} 6}^{2}+3 \cdot w_{\mathrm{ZPm} 60}^{2}+w_{\mathrm{rZ}}^{2}+ \\
w_{\mathrm{tTZ}}^{2}+w_{\mathrm{rMm} 6}^{2}+3 \cdot w_{\mathrm{rMm} 60}^{2}+4 \cdot w_{\mathrm{DZ}}^{2}+ \\
2 \cdot w_{\mathrm{DM}}^{2}+w_{\mathrm{ej}}^{2}+w_{\mathrm{FM}}^{2}+w_{\mathrm{TM}}^{2}+ \\
w_{\mathrm{TZ}}^{2}+w_{\mathrm{HyM}}^{2}
\end{array}\right) \\
& =4.3 \cdot 10^{-4} .
\end{aligned}
$$

The relative indication errors of the acquisition of the torque signal $w_{\text {AMD }}$ and of the transfer counter $w_{\text {ATZ }}$ enter as systematic error contributions to the measurement uncertainty, analogous to Equation (28). The other components of the transfer counter are included as contributions to the dynamic traceability of the torque measurement (Figure 9, path 5). The uncertainties of the counter $Z_{\mathrm{P}}$, of the standard $w_{\mathrm{ZPm}}$, and of its resolution are taken into account, analogous to Equation (28) with $m=6$ and $m=60$, respectively. Thereby, the components are included with $m=60$ for the link-up itself, for the determination of $E_{\text {korr }}$ and for the determination of $M_{0 \text {,rot }}$, i.e. three times. Therefore, $w_{\mathrm{rMm} 60}$ and $w_{\mathrm{DZ}}$ are also applied three times; in the case of $w_{\mathrm{DZ}}$, factor 4 appears because the drift of the counter $Z_{P}$ is also estimated with the value of $w_{\mathrm{DZ}}$. Components from the static intermediate testing of the torque measurement (Figure 9, path 5) do not enter, because these measurements only serve as a stability test of the torque measurement.

With Equations (14), (28), and (30) and the coverage factor $k=2$, the best measurement capability of the rotatory power measurement $W_{\mathrm{P}}$ yields

$$
W_{\mathrm{P}}=2 \sqrt{w_{\mathrm{n}}^{2}+w_{\mathrm{M}}^{2}}=8.7 \cdot 10^{-4}
$$

and the best measurement capabilities $(k=2)$ for the revolution speed $W_{\mathrm{n}}$ and for the rotatory torque $W_{\mathrm{M}}$ amount to

$$
W_{\mathrm{n}}=1.5 \cdot 10^{-4}
$$

and

$$
W_{\mathrm{M}}=8.5 \cdot 10^{-4} \text {. }
$$

The requirements that are placed on the national standard and are described in Section 2.2 are thus met.

To confirm the coverage factor $k=2$ in this measurement uncertainty budget, the effective degrees of freedom of the relative combined measurement uncertainty were determined according to Welch-Satterthwaite [15] to $v_{\text {eff }}=1315$ and applied to the student-t distribution. 
Table 2. Part 1. Symbols used in the text.

\begin{tabular}{|c|c|c|}
\hline Symbol & Unit & Description \\
\hline$A_{\mathrm{m}}$ & Ws & Work in the averaging interval \\
\hline$a_{\mathrm{x}}$ & 1 & $\begin{array}{l}\text { Cubic coefficients for the correction of the } \\
\text { linearity error of the torque sensor }(x=\{1,2,3\})\end{array}$ \\
\hline$E_{\text {korr }}$ & 1 & $\begin{array}{l}\text { Correction factor for the sensitivity drift of the } \\
\text { torque sensor }\end{array}$ \\
\hline$f_{\mathrm{M}}$ & $\mathrm{Hz}$ & Frequency of the torque signal \\
\hline$f_{\mathrm{Me}}$ & $\mathrm{Hz}$ & $\begin{array}{l}\text { Instantaneous value of the frequency of the } \\
\text { torque signal }\end{array}$ \\
\hline$f_{\mathrm{n}}$ & $\mathrm{Hz}$ & Frequency of the revolution speed signal \\
\hline$f_{\mathrm{R}}$ & $\mathrm{Hz}$ & $\begin{array}{l}\text { Reference frequency of the transfer counter } Z_{\mathrm{Tf}} \text {, } \\
10 \mathrm{MHz}\end{array}$ \\
\hline$f_{\text {Ref }}$ & $\mathrm{Hz}$ & Frequency of the reference pulse \\
\hline$f_{\mathrm{ZM}}$ & $\mathrm{Hz}$ & $\begin{array}{l}\text { Frequency of the counting pulse for the torque } \\
\text { measurement, } 32 \mathrm{MHz}\end{array}$ \\
\hline$f_{\mathrm{Zn}}$ & $\mathrm{Hz}$ & $\begin{array}{l}\text { Frequency of the counting pulse for the } \\
\text { revolution speed measurement, } 8 \mathrm{MHz}\end{array}$ \\
\hline$i$ & 1 & Continuous index \\
\hline$k$ & 1 & Coverage factor \\
\hline$m$ & 1 & $\begin{array}{l}\text { Averaging depth, only full number of revolution } \\
\text { periods of the measuring axis }\end{array}$ \\
\hline$M$ & $\mathrm{~N} \cdot \mathrm{m}$ & Torque \\
\hline$M_{0, \text { rot }}$ & $\mathrm{N} \cdot \mathrm{m}$ & Idle torque \\
\hline$M_{\mathrm{e}}$ & $\mathrm{N} \cdot \mathrm{m}$ & Instantaneous torque \\
\hline$M_{\mathrm{korr} 1}$ & $\mathrm{~N} \cdot \mathrm{m}$ & $\begin{array}{l}\text { Torque value after correction of zero drift and } \\
\text { sensitivity drift }\end{array}$ \\
\hline$M_{\text {korr2 }}$ & $\mathrm{N} \cdot \mathrm{m}$ & $\begin{array}{l}\text { Torque value after correction of the linearity } \\
\text { error }\end{array}$ \\
\hline$M_{\mathrm{m}}$ & $\mathrm{N} \cdot \mathrm{m}$ & Averaged torque \\
\hline$M_{\mathrm{S}}$ & $\mathrm{N} \cdot \mathrm{m}$ & Statically measured torque \\
\hline$n$ & $\min ^{-1}$ & Revolution speed \\
\hline$n_{\mathrm{e}}$ & $\min ^{-1}$ & Instantaneous revolution speed \\
\hline$p$ & 1 & Counting result \\
\hline$P_{\mathrm{e}}$ & W & Instantaneous power \\
\hline$P_{\mathrm{m}}$ & W & Averaged power \\
\hline$t$ & S & Time \\
\hline$t_{\mathrm{m}}$ & $\mathrm{S}$ & Duration of the averaging interval \\
\hline$u_{\mathrm{Pd}}$ & $\mathrm{S}$ & $\begin{array}{l}\text { MU of the period interval of the revolution speed } \\
\text { signal }\end{array}$ \\
\hline$u_{\mathrm{TZ}}$ & S & $\begin{array}{l}\text { MU of the difference between the gate time of } \\
\text { the focuses of the revolution speed counting and } \\
\text { that of the torque counting }\end{array}$ \\
\hline$w_{\mathrm{AMd}}$ & 1 & $\begin{array}{l}\text { Indication error of the torque measurement, } \\
\text { dynamic, counter } Z_{p}\end{array}$ \\
\hline $\mathrm{W}_{\text {Anr }}$ & 1 & $\begin{array}{l}\text { Relative indication error of the revolution speed } \\
\text { measurement, rotatory, counter } Z_{n}\end{array}$ \\
\hline$w_{\mathrm{ATZ}}$ & 1 & $\begin{array}{l}\text { Relative indication error of the transfer counter } \\
Z_{\mathrm{Tf}}\end{array}$ \\
\hline$w_{\mathrm{DM}}$ & 1 & Relative MU due to drift of the torque sensor \\
\hline$w_{\mathrm{DZ}}$ & 1 & $\begin{array}{l}\text { Relative MU due to long-term drift of the } \\
\text { counters }\end{array}$ \\
\hline$w_{\mathrm{ej}}$ & 1 & Relative jitter error of the encoded disc \\
\hline$w_{\mathrm{FM}}$ & 1 & Relative MU due to humidity of the torque sensor \\
\hline
\end{tabular}

Table 2. Part 2. Symbols used in the text.

\begin{tabular}{|c|c|c|}
\hline Symbol & Unit & Description \\
\hline$w_{\mathrm{HyM}}$ & 1 & Relative MU due to hysteresis of the torque sensor \\
\hline$w_{\mathrm{M}}$ & 1 & Relative combined MU of the torque measurement \\
\hline$W_{\mathrm{P}}$ & 1 & $\begin{array}{l}\text { Relative expanded total MU of the rotatory power } \\
\text { measurement }\end{array}$ \\
\hline$w_{\mathrm{Pd}}$ & 1 & $\begin{array}{l}\text { Relative MU of the revolution speed due to } \\
\text { triggering }\end{array}$ \\
\hline$w_{\text {Pd,e }}$ & 1 & $\begin{array}{l}\text { Relative MU of the revolution speed due to } \\
\text { triggering, instantaneous value }\end{array}$ \\
\hline$w_{\mathrm{Pd}, \mathrm{m}}$ & 1 & $\begin{array}{l}\text { Relative MU of the revolution speed due to } \\
\text { triggering (period interval), averaged value }\end{array}$ \\
\hline$w_{\mathrm{Pd}, \mathrm{m} 6}$ & 1 & $\begin{array}{l}\text { Relative MU of the revolution speed due to } \\
\text { triggering, averaged value from } 6 \text { periods }\end{array}$ \\
\hline$w_{\mathrm{Pd}, \mathrm{m} 60}$ & 1 & $\begin{array}{l}\text { Relative MU of the revolution speed due to } \\
\text { triggering, averaged value from } 60 \text { periods }\end{array}$ \\
\hline$w_{\mathrm{rMm}}$ & 1 & $\begin{array}{l}\text { Relative MU of the rotatory/dynamic torque } \\
\text { measurement due to the resolution of the data } \\
\text { transmission }\end{array}$ \\
\hline$w_{\mathrm{RMm}}$ & 1 & $\begin{array}{l}\text { Relative combined MU of the mechanical } \\
\text { traceability of the torque }\end{array}$ \\
\hline$w_{\mathrm{rMm} 6}$ & 1 & $\begin{array}{l}\text { Relative MU of the dynamic torque measurement } \\
\text { due to the resolution of the data transmission for } \\
m=6\end{array}$ \\
\hline$w_{\mathrm{rMm} 60}$ & 1 & $\begin{array}{l}\text { Relative MU of the dynamic torque measurement } \\
\text { due to the resolution of the data transmission for } \\
\mathrm{m}=60\end{array}$ \\
\hline$w_{\mathrm{RMr}}$ & 1 & $\begin{array}{l}\text { Relative MU of the rotatory traceability of the } \\
\text { torque sensor }\end{array}$ \\
\hline$w_{\mathrm{RMs}}$ & 1 & $\begin{array}{l}\text { Relative MU of the static traceability of the torque } \\
\text { sensor }\end{array}$ \\
\hline$w_{\mathrm{rn}}$ & 1 & $\begin{array}{l}\text { Relative MU of the revolution speed measurement } \\
\text { due to the resolution of the data transmission }\end{array}$ \\
\hline$w_{\mathrm{rn} 6}$ & 1 & $\begin{array}{l}\text { Relative MU of the revolution speed measurement } \\
\text { due to the resolution of the data transmission for } \\
m=6\end{array}$ \\
\hline$w_{\mathrm{rn} 60}$ & 1 & $\begin{array}{l}\text { Relative MU of the revolution speed measurement } \\
\text { due to the resolution of the data transmission for } \\
\mathrm{m}=60\end{array}$ \\
\hline$w_{\mathrm{rs}}$ & 1 & $\begin{array}{l}\text { Relative MU of the static torque measurement due } \\
\text { to the resolution of the data transmission }\end{array}$ \\
\hline$w_{\mathrm{rZ}}$ & 1 & $\begin{array}{l}\text { Relative MU of the transfer counter due to the } \\
\text { resolution }\end{array}$ \\
\hline$w_{\mathrm{TM}}$ & 1 & $\begin{array}{l}\text { Relative MU of the torque sensor due to } \\
\text { temperature }\end{array}$ \\
\hline$w_{\mathrm{Tn}}$ & 1 & Relative MU of the counters due to temperature \\
\hline$w_{\text {tTZ }}$ & 1 & $\begin{array}{l}\text { Relative MU of the transfer counter due to } \\
\text { triggering }\end{array}$ \\
\hline$w_{\mathrm{TZ}}$ & 1 & Relative MU of the transfer counter \\
\hline wZPe & 1 & $\begin{array}{l}\text { Relative MU of the counting for the torque } \\
\text { measurement, instantaneous value }\end{array}$ \\
\hline$w_{\mathrm{ZPm}}$ & 1 & $\begin{array}{l}\text { Relative MU of the counting for the torque } \\
\text { measurement, averaged value }\end{array}$ \\
\hline$w_{\mathrm{ZPm} 6}$ & 1 & $\begin{array}{l}\text { Relative MU of the counting for the torque } \\
\text { measurement, averaged value from } 6 \text { periods }\end{array}$ \\
\hline$w_{\mathrm{ZPm} 60}$ & 1 & $\begin{array}{l}\text { Relative MU of the counting for the torque } \\
\text { measurement, averaged value from } 60 \text { periods }\end{array}$ \\
\hline$w_{\mathrm{ZsMm}}$ & 1 & $\begin{array}{l}\text { Relative MU of the counting for the static torque } \\
\text { measurement, averaged value }\end{array}$ \\
\hline$\omega_{\mathrm{e}}$ & 1 & Instantaneous angular velocity \\
\hline$\Delta \mathrm{x}_{\mathrm{y}}$ & & $\begin{array}{l}\text { Influence quantity for uncertainty calculation, y: } \\
\text { index of standard uncertainties } w_{\mathrm{y}}\end{array}$ \\
\hline$W_{\mathrm{M}}$ & 1 & $\begin{array}{l}\text { Relative expanded total MU of the rotatory torque } \\
\text { measurement }\end{array}$ \\
\hline$w_{\mathrm{n}}$ & 1 & $\begin{array}{l}\text { Relative combined MU of the revolution speed } \\
\text { measurement }\end{array}$ \\
\hline$W_{\mathrm{n}}$ & 1 & $\begin{array}{l}\text { Relative expanded total MU of the revolution speed } \\
\text { measurement }\end{array}$ \\
\hline
\end{tabular}


Table 3. Abbreviations and designations used in the text.

\begin{tabular}{|c|c|}
\hline Symbol & Description \\
\hline BGBl. & Federal Law Gazette \\
\hline LMKM & $\begin{array}{l}\text { Guideline on metrological checks of medical devices with } \\
\text { a measuring function }\end{array}$ \\
\hline MPBetreibV & Medical Products Operating Ordinance \\
\hline MPG & Medical Devices Act \\
\hline MU & Measurement uncertainty \\
\hline NN & National standard \\
\hline PTB & Physikalisch-Technische Bundesanstalt \\
\hline RTD & rotational torque device \\
\hline $\mathrm{Tf}$ & Transfer standard \\
\hline $\mathrm{S}_{\mathrm{M}}$ & Torque signal \\
\hline $\mathrm{S}_{\mathrm{n}}$ & Revolution speed signal \\
\hline $\mathrm{S}_{\text {Ref }}$ & Reference pulse \\
\hline $\mathrm{S}_{\mathrm{ZM}}$ & Counting pulse for the torque measurement \\
\hline $\mathrm{S}_{\mathrm{Zn}}$ & Counting pulse for the revolution speed measurement \\
\hline $\mathrm{Z}_{\mathrm{M}}$ & $\begin{array}{l}\text { Counter for the number of periods of the torque signal } \\
\text { within a gate time }\end{array}$ \\
\hline$Z_{n}$ & $\begin{array}{l}\text { Counter for the period interval of the revolution speed } \\
\text { signal in periods of the counting pulse }\end{array}$ \\
\hline $\mathrm{Z}_{\mathrm{P}}$ & $\begin{array}{l}\text { Counter for the period interval of the torque signal in } \\
\text { periods of the counting pulse }\end{array}$ \\
\hline $\mathrm{Z}_{\mathrm{TF}}$ & Counter transfer standard \\
\hline
\end{tabular}

\section{SUMMARY}

The traceability of medical ergometers to national standards, which is stipulated by law in Germany, is ensured by a standard for rotatory power measurement that is operated at PTB. This standard is, in turn, linked up with PTB's national standards for time and static torque.

In order to ensure sufficient measurement uncertainty budgets for the traceability chain from the national laboratory down to the medical ergometers at all levels involved, the best measurement capabilities of $0.2 \%$ for the power in the range from $5 \mathrm{~W}$ to $1000 \mathrm{~W}$ and of $0.05 \%$ for the revolution speed in the range from $5 \mathrm{~min}^{-1}$ to $150 \mathrm{~min}^{-1}$ are stipulated. The analysis of the measurement uncertainties that have to be taken into account for the traceability and the operation of the standard for rotatory power shows that these requirements are being met and that the standard described is therefore suitable for fulfilling this legal task.

\section{REFERENCES}

[1] Public Health Service Publication No. 1000 - Series 2 - No. 21, Calibration of Two Bicycles Ergometers Used by the Health Examination Survey, Washington, D.C., 1967

[2] W. Sontopski, Kalibrierung und Qualitätssicherung bei elektronischen Ergometern (Calibration and constant quality for electronic ergometers), in: Standardisierung, Kalibrierung und Methodik in der Ergometrie (Calibration, standardizing and methodology in ergometry), H. Mellerowicz, I. W. Franz (editors). Perimed, Erlangen, 1982, pp. 26-33.
[3] E. Cramer, Performance requirements for bicycle ergometers, in: Progress in Ergometry: Quality Control and Test Criteria, Proc. of the Fifth International Seminar on Ergometry, Springer, 1984, pp. 170-173.

[4] G. Wegener, J. Andrea, Measurement uncertainty of torque measurements with rotating torque transducers in power test stands, Measurement 40, 7-8 (2007) pp. 803-810.

[5] A. Brüge, Influence of rotation on rotary torque transducers calibrated without rotation, Proc. of the XIV IMEKO World Congress, Tampere, Finland, 1-6 June 1997, vol. III, pp. 79-84

[6] D. Woods, I. Withers, The dynamic calibration of cycle ergometers; International Journal of Sports Medicine, 15, 4 (1994) pp. $168-171$.

[7] Gesetz über Medizinprodukte (Medical Devices Act - MPG), Official Gazette I, Aug. (1994) p. 1963, amendment: Official Gazette I, Jul (2017) p. 2757 [in German]. Online [Accessed 16 September 2019]:

http://www.gesetze-im-internet.de/mpg/index.html

[8] Verordnung über das Errichten, Betreiben und Anwenden von Medizinprodukten (Medical Products - Operating Ordinance MPBetreibV), Official Gazette I, Jun. (1998) p. 1762, amendment: Operating Ordinance 53, Jul. (2017) p. 2842 [in German]. Online [Accessed 16 September 2019]:

http://www.gesetze-im-internet.de/mpbetreibv/index.html

[9] S. Mieke, T. Schade (editors), Leitfaden zu messtechnischen Kontrollen von Medizinprodukten mit Messfunktion (Guide on the metrological verification of medical devices with a measuring function - LMKM) - Ausgabe 3.0 - Teil 1 und 2, PTB-Bericht MM-11, Physikalisch-Technische Bundesanstalt, Braunschweig, 12/2016, ISSN 0721-0906, ISBN 978-3-95606-296-4, [in German]

[10] R. Drahn, H. Pfeiffer, W. Riedel, H.-J. Thiemich, J. Tilgner, Prüfeinrichtung für medizinische Tretkurbelergometer (Testing device for medical pedal crank ergometers), PTB-Mitteilungen 105, Braunschweig 6/95, [in German].

[11] DIN VDE 0750-238:2002-10, Medizinische elektrische Geräte Teil 238: Besondere Festlegungen für die Sicherheit von Kurbelergometern (Medical electrical equipment - Part 238: Particular requirements for the safety of crank ergometers), Beuth Verlag GmbH, Berlin 2002, [in German].

[12] Betriebshandbuch, Beschreibung für dyncal100 - Eine Normalmesseinrichtung zur Bestimmung rotatorischer Leistungen (Description for dyncal100 - A standard measuring device for the determination of rotational powers), HBS GmbH, Rudolstadt, 2003, [in German].

[13] DIN 51309:2005-12, Werkstoffprüfmaschinen - Kalibrierung von Drehmomentmessgeräten für Statische Drehmomente (Materials testing machines - Calibration of static torque measuring devices), DIN Deutsches Institut für Normung e.V., Beuth-Verlag GmbH, Berlin, 2005-12, [in German].

[14] D. Peschel, PTB-Bericht (PTB report), PTB-1.22_96-024, Braunschweig, 1996, [in German].

[15] BIPM, JCGM 100:2008: Evaluation of measurement data - Guide to the expression of uncertainty in measurement. Online [Accessed 16 September 2019]: http://www.bipm.org/utils/common/documents/jcgm/JCGM $100 \quad 2008$ E.pdf 